\title{
Level Energies, Oscillator Strengths and Lifetimes for Transitions in Pb IV
}

Cite as: AIP Conference Proceedings 1058, 257 (2008); https://

doi.org/10.1063/1.3026457

Published Online: 27 October 2008

C. Colón, A. Alonso-Medina, A. Zanón, and J. Albéniz

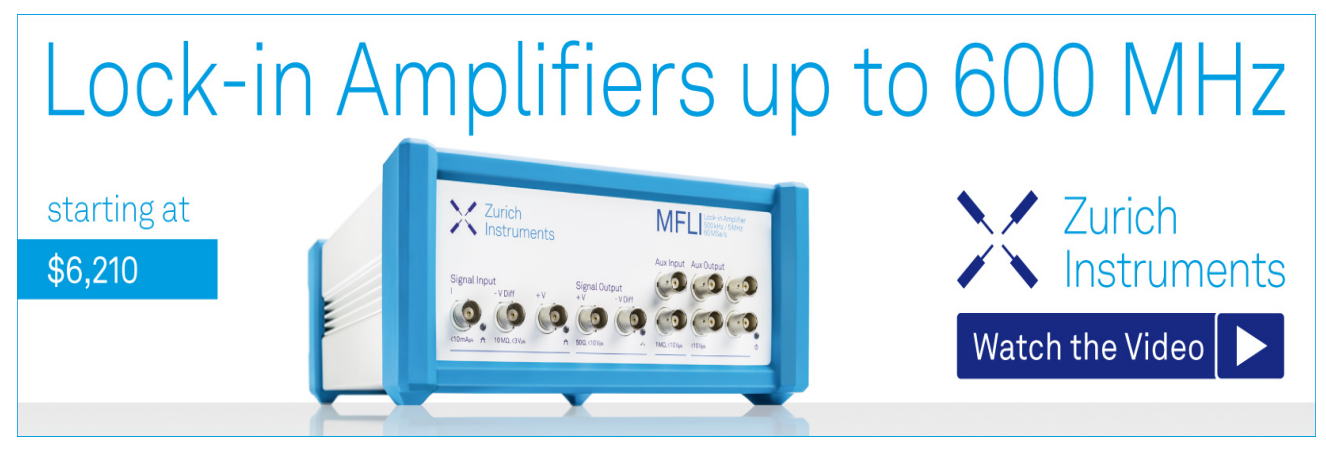




\title{
Level Energies, Oscillator Strengths and Lifetimes for Transitions in Pb IV
}

\author{
C. Colón ${ }^{\mathrm{a}}$, A. Alonso- Medina ${ }^{\mathrm{a}}$, A. Zanón ${ }^{\mathrm{b}}$ and J. Albéniz ${ }^{\mathrm{c}}$ \\ ${ }^{a}$ Dpto. de Fisica Aplicada. EUITI. Universidad Politécnica de Madrid (UPM) \\ ${ }^{b}$ Dpto. de Matemática Aplicada. EUITI. UPM \\ ${ }^{c}$ Dpto. de Quimica Industrial y Polimeros . EUTTI.UPM \\ Madrid Spain
}

\begin{abstract}
Oscillator strengths for several lines of astrophysical interest arising from some configurations and some levels radiative lifetimes of $\mathrm{Pb}$ IV have been calculated. These values were obtained in intermediate coupling (IC) and using $a b$ initio relativistic Hartree-Fock calculations. We use for the IC calculations the standard method of least square fitting of experimental energy levels by means of computer codes from Cowan. Transition Probabilities and oscillator strengths obtained, although in general agreement with the rare experimental data, do present some noticeable discrepancies that are studied in the text.
\end{abstract}

Keywords: Oscillator strengths, radiative lifetimes.

PACS: 31.15 . A-, 31.15.ag.

\section{THEORETICAL CALCULATIONS AND RESULTS}

Data on atomic properties are relevant not only to spectroscopy, these values are also of interest in a variety of other fields in physics and technology. The presence of $\mathrm{Pb}$ IV in stellar spectra has been reported in a few different type of stars. As an example the $\mathrm{Pb}$ IV resonance lines has been detected in Far Ultraviolet Spectroscopic Explorer (FUSE) spectra of hot subdwarf B (sdB) stars [1, 2].

In this work we present oscillator strengths for spectral lines arising from $5 \mathrm{~d}^{10} \mathrm{~ns}$ $(\mathrm{n}=7,8), 5 \mathrm{~d}^{10} 6 \mathrm{p}$ and $5 \mathrm{~d}^{10} 6 \mathrm{~d}$ configurations and some radiative lifetimes of $\mathrm{Pb} \mathrm{IV}$. We have obtained theoretical values of oscillator strengths in intermediate coupling (IC) using ab initio relativistic Hartree-Fock (HFR) calculations.

For the IC calculations we used the standard method of least-square fitting of experimental energy levels by means of computer codes from Cowan [3]. In this way, we obtained the LS composition of each level and the degree of configuration mixing. For the HFR calculations the Cowan computer code provide us the radial parts for determination of transition probabilities and initial estimated of the parameters for the IC fittings. The radial integrals for calculations of transition probabilities were obtained from the HFR wave-functions.

The system considered is complex, since at high $Z$ both relativistic and correlation effects are important. Although least-squares fitting of experimental energy level partially account correlations effects, both effects have been considered in this work. 
A most detailed description of this method can be seen in others works of these authors [4-7].

TABLE 1. Oscillator Strengths of spectral lines arising from $5 \mathrm{~d}^{10} 6 d$ and $5 \mathrm{~d}^{10} n s$ configuration and radiative lifetimes of $\mathrm{Pb} \mathrm{IV}$.

\begin{tabular}{|c|c|c|c|c|c|c|}
\hline \multicolumn{2}{|c|}{ Transition Levels } & \multirow{2}{*}{$\begin{array}{c}\text { Wavelength } \\
\lambda(\AA)^{\mathrm{a}}\end{array}$} & \multicolumn{2}{|c|}{ f-values } & \multicolumn{2}{|c|}{ Lifetimes (ns) } \\
\hline Upper & Lower & & This work & Others & $\begin{array}{r}\text { This } \\
\text { work }\end{array}$ & Others \\
\hline \multirow[t]{11}{*}{$6 \mathrm{~d}^{2} \mathrm{D}_{3 / 2}$} & $6 \mathrm{p}^{2} \mathrm{P}_{1 / 2}$ & 922.5 & 1.42 & $0.92^{b}$ & & \\
\hline & & & & $0.87^{\mathrm{b}}$ & & \\
\hline & & & & $1.19^{\mathrm{c}}$ & & \\
\hline & & & & $0.86^{\mathrm{c}}$ & & \\
\hline & $6 \mathrm{p}^{2} \mathrm{P}_{3 / 2}$ & 1144.9 & 0.114 & $0.088^{b}$ & & \\
\hline & & & & $0.092^{b}$ & & \\
\hline & & & & $0.12^{\mathrm{c}}$ & & \\
\hline & & & & $0.093^{\mathrm{c}}$ & & \\
\hline & & & & & 0.16 & $0.28 \pm 0.03^{\mathrm{d}}$ \\
\hline & & & & & & $0.281 \pm 0.025^{\mathrm{e}}$ \\
\hline & & & & & & $0.234 \pm 0.010^{\mathrm{e}}$ \\
\hline \multirow[t]{4}{*}{$6 \mathrm{~d}^{2} \mathrm{D}_{5 / 2}$} & $6 p^{2} \mathrm{P}_{3 / 2}$ & 1116.1 & 1.06 & & & \\
\hline & $5 d^{9} 6 s 6 p\left[4^{\circ}\right]_{3 / 2}$ & 8749.8 & 0.00046 & & & \\
\hline & & & & & 0.26 & $0.36 \pm 0.02^{\mathrm{e}}$ \\
\hline & & & & & & $0.34 \pm 0.02^{\mathrm{e}}$ \\
\hline \multirow[t]{5}{*}{$7 \mathrm{~s}^{2} \mathrm{~S}_{1 / 2}$} & $6 \mathrm{p}^{2} \mathrm{P}_{1 / 2}$ & 917.9 & 0.25 & $0.17^{b}$ & & \\
\hline & & & & $0.16^{\mathrm{c}}$ & & \\
\hline & $6 \mathrm{p}^{2} \mathrm{P}_{3 / 2}$ & 1137.9 & 0.20 & $0.23^{b}$ & & \\
\hline & & & & $0.22^{c}$ & & \\
\hline & & & & & 0.25 & $0.35 \pm 0.5^{\mathrm{d}}$ \\
\hline \multirow[t]{14}{*}{$8 \mathrm{~s}^{2} \mathrm{~S}_{1 / 2}$} & $6 \mathrm{p}^{2} \mathrm{P}_{1 / 2}$ & 576.4 & 0.032 & $0.027^{c}$ & & \\
\hline & $6 \mathrm{p}^{2} \mathrm{P}_{3 / 2}$ & 656.1 & 0.028 & $0.029^{c}$ & & \\
\hline & $5 \mathrm{~d}^{9} 6 \mathrm{~s} 6 \mathrm{p} \quad\left[4^{\circ}\right]_{3 / 2}$ & 1346.9 & 0.00019 & & & \\
\hline & $5 \mathrm{~d}^{9} 6 \mathrm{~s} 6 \mathrm{p}\left[10^{\circ}\right]_{1 / 2}$ & 1802.2 & 0.00030 & & & \\
\hline & $5 \mathrm{~d}^{9} 6 \mathrm{~s} 6 \mathrm{p} \quad\left[9^{0}\right]_{3 / 2}$ & 1795.9 & 0.00014 & & & \\
\hline & $5 \mathrm{~d}^{9} 6 \mathrm{~s} 6 \mathrm{p}\left[12^{\circ}\right]_{3 / 2}$ & 2015.6 & 0.00046 & & & \\
\hline & $5 d^{9} 6 s 6 p\left[13^{\circ}\right]_{1 / 2}$ & 2075.8 & 0.016 & & & \\
\hline & $5 d^{9} 6 s 6 p\left[15^{\circ}\right]_{3 / 2}$ & 2464.1 & 0.054 & & & \\
\hline & $5 d^{9} 6 s 6 p\left[16^{\circ}\right]_{1 / 2}$ & 2509.6 & 0.28 & $0.26^{\mathrm{c}}$ & & \\
\hline & $5 \mathrm{~d}^{9} 6 \mathrm{~s} 6 \mathrm{p}\left[17^{\circ}\right]_{1 / 2}$ & 2546.8 & 0.078 & & & \\
\hline & $5 d^{9} 6 s 6 p\left[19^{\circ}\right]_{3 / 2}$ & 2874.2 & 0.044 & & & \\
\hline & $5 \mathrm{~d}^{9} 6 \mathrm{~s} 6 \mathrm{p}\left[22^{\circ}\right]_{3 / 2}$ & 3146.4 & 0.22 & $0.35^{\mathrm{c}}$ & & \\
\hline & $5 d^{9} 6 s 6 p\left[25^{\circ}\right]_{1 / 2}$ & 5370.1 & 0.0030 & & & \\
\hline & & & & & 0.41 & $0.47 \pm 0.04^{\mathrm{e}}$ \\
\hline
\end{tabular}


Several of the values calculated in this work are the first presented in the bibliography. Levels no designed by Moore [8] have been assigned in this work.

In table 1 we present oscillator strengths of spectral lines arising from $5 \mathrm{~d}^{10} 6 \mathrm{~d}$ and $5 \mathrm{~d}^{10} \mathrm{~ns}$ configurations and some radiative lifetimes. In Table 2 we present as example the results obtained for two lifetimes corresponding to resonance lines of $\mathrm{Pb} \mathrm{IV}$ of high astrophysical interest.

TABLE 2. Radiative lifetimes of resonant lines of $\mathrm{Pb} I V$.

\begin{tabular}{rrrrr}
\hline Upper & $\begin{array}{c}\text { Transition } \\
\text { Lower }\end{array}$ & $\begin{array}{c}\text { Wavelength } \\
(\mathbf{n m})^{\mathrm{a}}\end{array}$ & $\begin{array}{c}\text { Lifetimes (ns) } \\
\text { This work }\end{array}$ & Others \\
\hline $6 \mathrm{p}^{2} \mathrm{P}_{1 / 2}$ & & & & \\
$6 \mathrm{p}^{2} \mathrm{P}_{3 / 2}$ & $6 \mathrm{~s}^{2} \mathrm{~S}_{1 / 2}$ & 131.3 & 0.95 & $1.11 \pm 0.10^{\mathrm{d}}$ \\
\hline${ }^{a}$ Moore 1958 & ${ }^{d}$ Ansbacher et al & 102.9 & 0.48 & $0.52 \pm 0.04^{\mathrm{d}}$ \\
\hline
\end{tabular}

There is a good agreement between our results and the experimental values found in the bibliography [9-12].

\section{ACKNOWLEDGMENTS}

This work has been supported by the project CCG07-UPM/ESP-1632 of the TECHNICAL UNIVERSITY OF MADRID (UPM). Support to the lines of UPM investigation groups included in the IV PRICIT of the CAM (Comunidad Autonoma de Madrid), SPAIN.

\section{REFERENCES}

1. P. Chayer, M. Fontaine, G. Fontaine, F. Weselmael and J. Dupuis, Baltic Astronomy 15, 131-137 (2006).

2. S. J. O'Toole, Astronomy and Astrophysics 423, L23-L28 (2006).

3. R. D. Cowan, Theory of Atomic Structure and Spectra, edited by University Press, Los Angeles, 1981.

4. C. Colón and A. Alonso-Medina, Physica Scripta 62, 132-136 (2000).

5. C. Colón and A. Alonso-Medina, Astronomy and Astrophysics 422, 1109-1112 (2004).

6. A. Alonso-Medina, C. Colón and C. Rivero Physica Scripta 71, 154-158 (2005).

7. A. Alonso-Medina, C. Colón and A. Zanón, Mon. Not. R. Astron. Soc.385, 261-268 (2008).

8. C. E. Moore, in Atomic Energy Levels, edited by NBS 467, Washington D. C., 1958.

9. J. Migdalek and M. Garmulewicz, J. Phys B: At. Mol. Opt. Phys. 33, 1735-1743 (2000).

10. U. I. Safronova and W. R. Johnson, Phys Rew. A 69, 052511-9 (2004).

11. W. Ansbacher, E. H. Pinnington and J. A. Kernahan, Can. J. Phys. 66, 402-404 (1988).

12 E. H. Pinnington, W. Ansbacher, A. Tauheed and J. A. Kernahan, Can. J. Phys. 69, 594-596 (1991). 